\title{
Universiteit
}

Leiden

The Netherlands

\section{Teacher reflection on action: What is said (in research) and what is done (in teaching).}

Mena Marcos, J.J.; Sánchez Miguel, E.; Tillema, H.H.

\section{Citation}

Mena Marcos, J. J., Sánchez Miguel, E., \& Tillema, H. H. (2009). Teacher reflection on action: What is said (in research) and what is done (in teaching). Reflective Practice, 10(2), 191-204. Retrieved from https://hdl.handle.net/1887/15087

Version: $\quad$ Not Applicable (or Unknown)

License: $\quad$ Leiden University Non-exclusive license

Downloaded from: $\quad$ https://hdl.handle.net/1887/15087

Note: To cite this publication please use the final published version (if applicable). 


\title{
Teacher reflection on action: what is said (in research) and what is done (in teaching)
}

\author{
Juan José Mena Marcos ${ }^{\mathrm{a}}$, Emilio Sánchez Miguel ${ }^{\mathrm{a}}$ and Harm Tillema ${ }^{\mathrm{b} *}$ \\ ${ }^{a}$ Universidad de Salamanca, Spain; ${ }^{b}$ Department of Education, Leiden University, The \\ Netherlands
}

Teacher reflection on action has been studied extensively in the last 25 years. To appreciate the concept and its use, we should look at the key features of reflection on action (TRA) as identified in research and what teachers state is typical of reflection. In three other studies we have explored possible alignments among (1) what has been claimed (using 50 conceptual papers); (2) what has been disseminated to teachers (using 122 articles on teacher development); and (3) what has been described by teachers (analyzing 49 teacher accounts of reflection practices). As a result of this exploration, we found little empirical evidence for what has been stated in theoretical essays. The research-based papers revealed that the studies conducted were not very relevant for key characteristics of TRA as identified by the theoretical papers. Furthermore, in attempting to gauge teachers' reflections, the research does not really reflect what is advocated by models of reflection. These findings led us to conclude that the concept of teacher reflection on action is still very much in flux and may not be adopted as intended in programs of teacher professional development and teacher education.

Keywords: reflection on action; teaching; teacher professional development; teacher education; research on teaching; teacher learning

\section{Introduction}

The concept of teacher reflection has been advocated in the literature on teaching and teacher education for several decades, and has been given many meanings (Edwards, Gilroy \& Hartley, 2002). What is commonly described as reflection is a process in which teachers conceive their work as subject to self-examination and continuous learning (Van Manen, 1997). Regardless of nuance, the central idea in research literature is that through reflection the teacher better understands and extends his/her professional activity, and that reflecting on teaching problems will lead to new insights for practice. The claim is that the overall benefit of this process of scrutiny is that it will enrich, systematize and construct professional knowledge (Carr \& Kemmis, 1988; Cochran-Smith \& Zeichner, 2005; Elliot, 1991; Kemmis \& McTaggart, 1988; Liston \& Zeichner, 1993). However, despite the various positions on reflection and the many articles that promote or justify these ideas (theoretical essays, meta-analyses and research studies; see Edwards et al., 2002), it is still an open issue whether proposals, often framed as models to enhance reflective practice, align with actual processes

\footnotetext{
*Corresponding author. Department of Education, Leiden University, PO Box 9555, NL 2300
} RB Leiden, The Netherlands. Email: tillema@fsw.leidenuniv.nl 
that describe the nature of these reflections on behalf of actual teachers (Kane, Sandretto \& Heath, 2002).

Given the wealth of prescriptive essays (those that encourage reflection on action in teaching), it is still a question whether key features identified in conceptual and research-based models have any bearing on actual practice and may, if what is claimed as a ground for reflection, be recognized in actual reflection in teaching. The extent to which the talk and the walk (Mena Marcos \& Tillema, 2006) are present may indicate the grounding of the concept of reflection and add to the legitimacy or authenticity of development programs (for teacher education). This article aims to describe the relationship between what are claimed as key elements of reflection and disseminated to teachers, and compares them to what teachers actually indicate as reflection characteristics of value in their practice. Our research does this by examining three different studies to reveal the various aspects involved in how knowledge on Teacher Reflection on Action (TRA) is constructed in different domains (or discourses). These are: research (validated knowledge construction); teacher education/dissemination (knowledge sharing); and practice (professional knowledge development). Using this three-way contrast of domains in which reflection as a concept operates, we tried to reveal possibilities for integrating findings among the domains (or put differently, aligning the world of teaching and research better on the issue of reflection). More specifically, and following Sanchez's notions on integrating research findings (Sánchez, 2001), this article focuses on linkages among the following levels:

(1) What is conceptually grounded (known) in teacher reflection on action?

(2) What is prescriptively proposed as teacher reflection on action?

(3) What is actually stated that teachers do in practice when they are involved in a process of reflection on their action?

Figure 1 reveals the interrelationship among these questions.

According to this diagram, a knowledge base specifies (key) features and characteristics with regard to TRA; this base should be substantiated or based on empirical research. Ideally, the (key) features of reflection are coherently identified in theories as central to the process and use of reflection on action. The diagram indicates the interconnectedness of a conceptualization of reflection with other domains in which reflection is used, i.e. research, practice and development. What is said and done with regard to reflection should be aligned, or at least be recognizably shared, among domains. To evaluate whether a coherent and shared set of features stemming from a knowledge base on TRA is being used, we looked for correspondences among the three domains depicted in the diagram. The basis of our appraisal was: how is knowledge on TRA mutually understood.

Following the diagram, a first level of comparison is between: what is said and what is known. This gauges the contrast between notions stated in the conceptual/ theoretical literature on reflection and the available empirical knowledge base gained from research. The paradigm of teacher (action) researchers (Cochran-Smith \& Lytle, 1993 ) is a major platform for specifying the key characteristics of teacher reflection that can also be confirmed empirically (since the relationship is made explicit in the paradigm). We therefore analyzed international research studies embedded in this paradigm (a sample of 50 articles published in the last decade) to identify which key features of teacher reflection were acknowledged. 


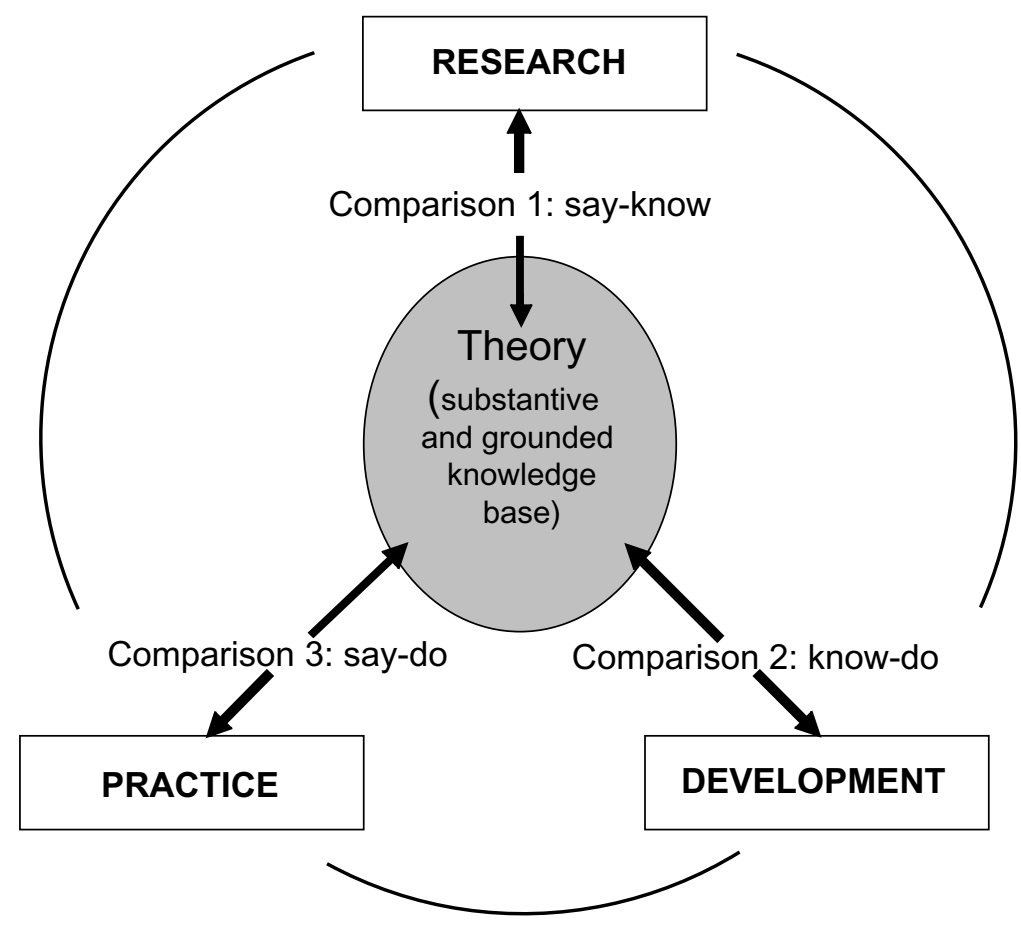

Figure 1. A comparative framework on domains of teacher reflection on action.

A second level of comparison, i.e. between what is known and what is (proposed to be) done deals with characteristics that advocate and promote reflection on action. McAlpine and Weston (2000) analyzed whether these proposals were corroborated by research. We chose 122 articles from teacher development journals to establish whether the proposals on teacher reflection on action were empirically substantiated. What is claimed should correspond to what is proposed to teachers.

Finally, a third level of comparison is between what is said that is done. Here we examined what is known and claimed as key features of teacher reflection on action and compared them with what is said to be done by teachers, derived from teacher accounts of their reflective practice. The aim was to measure the distance between what is advocated in reflective practice (i.e. through professional development programs) and what is actually done by teachers. We analyzed 49 samples of teaching practice in which experiences of action research and reflection were described.

\section{Study 1. What is said and known about Teacher Reflection on Action?}

There has been a great deal of teacher research in the last two decades. Several authors have variously classified this research as: research carried out by teachers (Cochran-Smith \& Lytle, 1993), research in action (Carr, 1989), reflective inquiry (Schön, 1984/1992, 1987/1992), or practice as inquiry. There are many variants of this teacher originated practical research in which teachers as researchers scrutinize their practice. The research can be encountered under different labels, such as collaborative action research, teacher reflection, participative action research, critical 
reflection, ethical reflection, etc. (Mudler, Swaak \& Kessels, 2004). Two main conceptions or ideas can be identified within the paradigm.

\section{Teacher (action) research}

In spite of the various meanings in the literature, reflection is defined as a cyclical problem-solving process, carried out in a systematic and intentional (deliberate) way in which theory (envisaged as research-based concepts) is related to practice. This cognitive process comprises other sub-processes of thought and action such as: planning, evaluation, observation and collaboration. The key characteristics of teacher reflection on action can be summarized as follows: which:

It is a problem-solving process (having action research cycles, Lewin, 1946)

(1) Links theory (teaching beliefs) and practice to improve education (Kessels \& Korthagen, 1996; Schön, 1983, 1987);

(2) Implies systematic research and intentional inquiry on practice (Little \& Cochran-Smith, 1990; Zeichner, 1993);

(3) Consists of processes of thought and action entailing steps: goal setting, planning, observation, and collaboration (Clarke, 2006; Kemmis \& McTaggart, 1988; McNiff, 1998).

\section{Teacher reflection (on action)}

In a different but related realm, reflection is regarded as a meta-cognitive process that implies an awareness of what an individual does and thinks (having a mental conception of it); it consists of exploring personal beliefs, thoughts and actions (internal analysis) in a deliberate, biographical and critical (non-superficial and often narrative) way. Often this process becomes part of the action-research cycle. The key characteristics of such a reflective process can be summarized as follows:

It is a meta-cognitive process, i.e. comprised:

(1) Personal thought: involving (a) mental imaging (self-awareness) of acts and (b) self-exploration of beliefs, thoughts and actions (King \& Kitchener, 2004; MacLellan, 2003).

(2) Deliberate action: mental exploration is meant to be intentional, aimed at clarifying the context of practice, and relating it to pedagogical contents (LaBoskey, 1994; McAlpine \& Weston, 2000).

(3) Critical reasoning: thinking about the consequences (personal, ethical or social) that reflect beliefs, thoughts, and actions (Johnson, 1995; Osterman, 1990; Price \& Valli, 2005; Ziegahn, 2005).

Both conceptualizations view reflection as self-inquiry about an individual's actions. Therefore, action research and reflection on action are linked processes. From the point of view of teacher action research, reflection is shaped as a process of problem solving, whereas from a reflection on action viewpoint, teacher research would be an activity oriented process of gaining awareness and scaffolding (self) inquiry (Westberg, 2001). We were thus able to identify the following key characteristics of teacher reflection on action in the literature as: 
(1) A (meta)cognitive problem-solving process, cyclical in nature, that consists of (a) initial beliefs about a given concern or problem, (b) plans of action to improve practice with respect to such concern, (c) teaching action taken, and (d) review of solutions or looking back on what has been done.

(2) A deliberate, personal, and recurrent process that generates professional knowledge through study and inquiry either on teaching practice itself or its determining factors (curricular, institutional, and ideological aspects).

\section{Method}

The question pursued in this study is the extent to which what is stated (theoretically) about teacher reflection key characteristics is validated by empirical research. We referred to international articles published in a five-year period (2001-2007). These peer-reviewed articles were extracted from relevant education journals and major databases (PsycINFO, ERIC, Current Contents, Web of Science). Our search included key words on (1) reflection, (2) action, (3) beliefs. The search resulted in a sample of 89 studies, of which 50 were selected that contained empirical data about researched teacher practices on reflection.

\section{Findings and discussion}

One key characteristic of teacher reflection on action we identified from the conceptual and research literature was a deliberate problem-solving process that consists of two intertwined components: action and thought. This combined or intertwined feature has been further circumscribed by several authors in different ways (following Schön, 1983) as: practical wisdom (Shulman, 1987), pondered action (Clark \& Hollingsworth, 2002), circumstantial understanding (Bereiter, 2002), or situational knowledge (Leinhardt, 1988). Meta-analytic studies (see Mena Marcos \& Tillema, 2006) emphasize it as a process that combines knowledge and action, which runs through cycles of: (1) a given concern or problem; (2) plans of action; (3) teaching action taken; and (4) review of solutions.

Our analysis of publications also reveals that hardly any of these studies gauges reflection as a complete, i.e. cyclical process of problem solving (entailing all key characteristics). Instead, they study reflection as a process dealing with certain aspects or fragments. Only $8 \%$ of the studies reviewed take into account all aspects of the deliberate problem-solving process, whereas the other $92 \%$ revert to analyzing only several aspects; more specifically, $24(48 \%)$ focus on beliefs, six $(12 \%)$ on teacher goals, $28(56 \%)$ on reflective thoughts, and $11(22 \%)$ on action after reflection.

This fragmented focus in studies on teacher reflection may hinder a full understanding or integrated account of the process. Nevertheless, findings from these studies depict a grim view on reflection as it is practiced: only $0-10 \%$ of teachers are capable of carrying out the task of reflecting on practice. Butler, Novak, Jarvis-Selinger, \& Beckingham (2004) mention that none of the 10 teachers they studied over a two-year period were able to establish clear goals and evaluate results for their practice. McLellan (2004) states that only $2 \%$ of 40 teachers were aware of the cyclical reflection steps: identifying a problem, setting a goal, solving the problem and evaluating the results. The highest percentages of reflective ability were reached in a study by Tillema (2006), where 10\% of the teachers included comments referring to a cyclical reflective process of problem solving and goal setting. 
In the only pre-post study of our review (Butler et al., 2004), 70\% of teachers reflect by setting clear goals and evaluate the results when trained.

Our search found empirical support in the studies reviewed for at least three of the above-mentioned key characteristics of teacher reflection on action:

(1) Deliberate action. Studies evaluated the extent to which teacher knowledge (i.e. pedagogical content knowledge) is a necessary ingredient for successful reflection. Griffin (2003) showed that $45 \%$ of the teachers use pedagogic language when referring to concepts and contents of reflection, whereas Braun and Cumpler (2004) arrived at 58\% of teachers that use reflective terms.

(2) Critical reasoning. In the studies reviewed, being critical is one of the most appreciated (and studied) aspects in reflection. McLellan (2004) states that only $6.5 \%$ of teacher reflections are of a critical nature. Price and Valli (2003) showed that none of the teachers in their study was critical; they only produced reflections of an instrumental kind. The most promising score was reported by Kember et al. (2000) in their study, where teachers reached an average score of 12.5 (max. 20) on a scale of critical reflection.

(3) Personal thought. One study considered a teacher's autonomy in thinking as an essential feature of a reflective professional (Smith \& Tillema, 2001). It was found that professionals capable of self-regulation made their own reflective decisions on an average of 7 on a scale of 1 to 10 . In addition, Masui \& De Corte (2005) measured self-regulated learning through reflection as a basic component. However, there appeared to be little capacity for personal reflection. Reflective behaviour was shown to be slightly higher when teachers were trained in self-regulated thinking.

\section{Study 2: What is known about development of teacher reflection}

As a second level of comparison, we gauged how the proposed reflection models given to teachers are substantiated empirically (based on journal articles). This was done to determine whether teachers are provided with validated tools for their practice. More specifically, we gauged:

(1) What are offered as models for improvement of reflective practice through a search of published proposals on reflection on action to be implemented by teachers?

(2) Is there a connection (or reference) between what is proposed and established theoretical or empirical support? This led to a propositional analysis of substantiated claims in grounded theory as referred to in the proposed models. Or alternatively, if proposals are based on empirical research.

\section{Method}

A discourse analysis was undertaken of 122 articles in teacher development journals (each usually about 4-5 pages) that contain models and proposals to improve teacher reflection. Articles were collected from two widely distributed Spanish journals: Cuadernos de Pedagogía and Revista de Aula de Innovación Educativa (issues from 1985-2004). These journals specifically address teacher development issues. The selection of articles was based on: (1) a written record of a reflection model proposal; 
(2) the proposal has been practiced; and finally; (3) the proposal was supported in the field by colleagues.

\section{Analysis}

The analysis of articles consisted of four steps: (1) Selection of text information; (2) segmentation into propositions; (3) classification of propositions; and (4) topic hierarchy. Once all propositions had been classified according to topic, they were placed in hierarchical categories by structuring the list of topics according to the density of contents per topic. The inter-rater reliability coefficient reached in each step was: $\mathrm{k}_{1}$ $=0.79 ; \mathrm{k}_{2}=0.83 ; \mathrm{k}_{3}=0.93 ; \mathrm{k}_{4}=1$.

We then analyzed how each article substantiated any proposed feature of reflection. This was coded in four categories: justification given (why), contents described (what), methodology (how), and limits (conditions). The categories were further detailed in subcategories as shown in Table 1. Reliability of coding was assessed by classifying 15 randomly selected texts (fragments) $(\mathrm{k}=0.90)$.

\section{Findings and discussion}

Table 1 presents the findings from our coding analysis.

Table 1 reveals that articles promoting teacher reflection most frequently delineate reflection attributes (i.e. involving teacher collaboration, systematicity, etc.), by providing explications (aspects to study, analyze or reflect upon space and time, classroom dynamics, etc.) and referring to the cost of a proposal. These categories constitute $69.8 \%$ of the articles' contents, whereas necessary preparation, procedures, principles, or obstacles and difficulties in implementation are less frequently addressed. These findings show that the 'how' (learning to reflect) received much less attention than the 'what' (explaining a reflection model). Only $31.2 \%$ of the content (the sum of categories: procedure, explications, contents for reflection and principles) explicitly aimed at development in teachers.

Almost half of the proposals could be linked to conceptual references (42.91\%); these were classified in two categories: (1) content justified by the literature on teacher reflection and (2) content explained in the limits of the proposal, i.e. with reference to

Table 1. Categories of reflection dealt with in proposals to develop reflection.

\begin{tabular}{llcr}
\hline Categories & Subcategories & No. of propositions & $\%$ \\
\hline JUSTIFICATION & I. Context & 110 & 7.28 \\
Why & & & \\
$(7.28 \%)$ & & 184 & 12.19 \\
CONTENTS & II. Principles & 222 & 14.71 \\
What & III. Explications & 423 & 28.03 \\
$(54.93 \%)$ & IV. Attributes & 65 & 4.30 \\
METHODOLOGY & V. Procedures & 146 & 9.67 \\
How & VI. Training & & 3.64 \\
$(13.97 \%)$ & & 55 & 5.89 \\
LIMITS & VII. Difficulties & 89 & 14.18 \\
Conditions & VIII. Obstacles & 214 & 100 \\
$(23.71 \%)$ & IX. Costs & 1509 & \\
& TOTAL & &
\end{tabular}


costs. Only a few articles provide a theoretical, empirical or programmatic justification to validate the proposals made to teachers. Of 1509 text (topical) fragments collected, only 172 referred to research studies $(9.31 \%)$; those presenting empirical data only represent a total of $11(0.72 \%)$. This means that the vast majority of articles substantiate reflection proposals (over 90\%) without any empirical or theoretical backing.

\section{Study 3: What teachers do when reflecting on action}

The next level of our study included an analysis of key features of teacher reflection, comparing them with what teachers actually say they do when reflecting. More specifically, we were interested in what teachers explain about what they do when reporting about their practice. This analysis was intended to gauge the reflection features used and grounded in teacher reflection on action. We looked for both content and procedure: (1) what they thought (values, problems, goals); (2) what they did (solutions); and (3) what they reflected on (appraisals and obstacles); more specifically, we analyzed: (1) completeness of reflection with regard to coverage of key features (see underlined features above); and (2) the cyclical or recurrent problem-solving nature of reflection on action that qualified it as teacher action research.

\section{Method}

A sample of 49 written reflective accounts by teachers was collected from articles published in a Spanish professional journal that contained publications written by and for teachers, Cuadernos de Pedagogía (Accounts of Pedagogy). The journal provides a forum for teachers to present their work in a non-framed, authentic way. The guidelines do not restrict teachers to a fixed format, but encourage them to present their work descriptively. Instructions to authors favour narrative accounts as well as conceptualizations of practice. Forty-nine articles written by teachers were selected from 12 issues of this journal from 2001 to 2005 ; the average length was 3-5 pages. The content of the articles was analyzed in four steps: step (1), selection of text fragments; step (2), identification of propositions; step (3), identification of key features referred to; step (4), topical analysis. The degree of inter-rater agreement obtained for the topical analysis ranged from 0.71 to 0.97 .

\section{Findings and discussion}

An overview of topic components found in the teachers' reflective accounts is given in Figure 2. Of the 553 propositions analyzed, the vast majority was oriented towards values, i.e. beliefs about a need to change $(200 \mathrm{pp}$. or $36 \%)$. The greatest number addressing a particular feature in the reflective accounts is found in Review of Plans, followed by the combination Appraisals and Obstacles (222 pp. or 39.78\%). To date, teachers more often indicated the positive effects of their practices, appraisals (181 pp. or $32.73 \%$ ) rather than obstacles. The low frequency of features dealing with Problem Definition (14 pp. or 2.53\%) is also notable. The feature, Concern, which implicitly reflects a Problem Statement, is included in $69 \mathrm{pp}$. accounting for $12 \%$.

This analysis shows that teachers' goals and values account for the highest percentage, meaning they are intended to solve problems (aim at solutions) by reflection. Reflections seem justify and legitimize a solution found. But above all, teachers are concerned with values $(45.03 \%)$. It is also notable that teacher reflections tend 


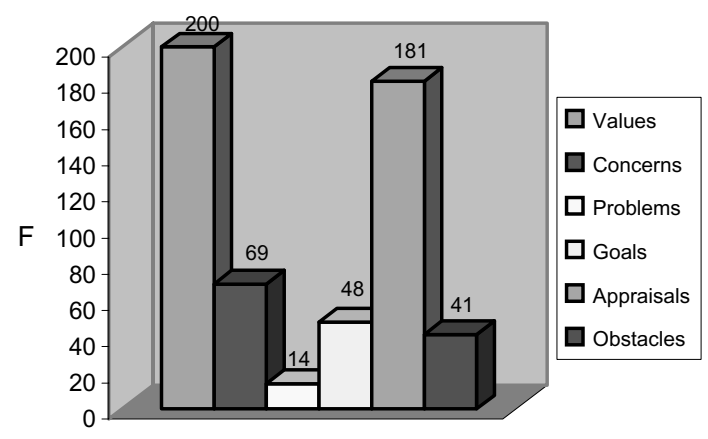

Figure 2. Frequencies of categories in teacher reflection on action.

to stress the positive aspects (appraisals) of actions rather than the negative ones (obstacles).

With respect to the nature of the reflective process, each article was further screened on the completeness of reflection (see Table 2).

We were able to identify 13 different reflective patterns, which indicates that there is no fixed way teachers conduct reflection. Four main types were obtained from this analysis based on frequency of problem-solving features.

(1) Evaluative reflection (pattern 1.4 and 2.5, $\mathrm{n}=9$ ) involve a description of what has been done and an appraisal of it.

(2) Problem-based reflection (patterns 2.3 and 3.3, $n=4$ ) involves an appraisal of what has been achieved with respect to the initial problem.

Table 2. Reflective patterns found in written accounts of teachers.

\begin{tabular}{llrr}
\hline & & $\mathrm{f}$ & $\%$ \\
\hline $\begin{array}{c}\text { Accounts dealing with no } \\
\text { component or key }\end{array}$ & 0. & 1 & 2.1 \\
characteristic of teacher & & & \\
reflection on action. & & & \\
Accounts dealing with & 1.1. Problem only & 0 & 4.1 \\
only a single category & 1.2. Concern only & 0 & 6.1 \\
step. & 1.3. Plan for change only & 2 & \\
& 1.4. Review of plan only & 3 & \\
Accounts with two & 2.1. Problem and concern. & 0 & 2.0 \\
components. & 2.2. Problem and plan for change & 1 & 4.0 \\
& 2.3. Problem and review of plan & 2 & 12.2 \\
& 2.4. Concern and plan for change & 0 & 22.5 \\
& 2.5. Concern and review of plan & 6 & \\
2.6. Plan for change and review of plan & 11 & \\
Accounts with three & 3.1. Problems, concern and plan for change & 0 & 4.1 \\
components. & 3.2. Problem, plan for change and review & 2 & 4.1 \\
& 3.3. Problem, concern, review & 2 & 24.5 \\
Accounts with four & 3.4. Concern, plan for change and review & 12 & \\
components. & 4. Problems, concern, plan for change. and review. & 7 & 14.3 \\
& & & \\
& TOTAL & 49 & 100 \\
\hline
\end{tabular}


(3) Deliberate reflection (patterns 2.6 and 3.4, $\mathrm{n}=23$ ) involves setting up a clear, specific plan for change that a teacher uses to embark on an action.

(4) Cyclical reflection. (patterns 3.2 and $4, n=9$ ): completes the presence of features of reflection in which the teacher works explicitly with three essential components: (a) problem, (b) plan and (c) review.

With regard to completeness of reflective accounts (the extent to which an article contains all key features of reflection), only four of 55 articles showed complete coverage of all reflective components. Full coverage is also associated with a full process, i.e. cyclical and recursive. On average, each article included 1.22 specific appraisals (from a mean of 3.89 appraisals); the same was true for obstacles: on average, 1.67 contained complete reflections (from a mean of 3.65). Nevertheless, these differences are not statistically significant ( $p=0.16$, according to the Mann-Whitney $U$ test); for obstacles, this was significant, but only marginally ( $p=0.057)$.

Apart from completeness, we also gauged whether teacher reflection contained a cyclical, recursive process (i.e. going back and forth between solutions and goals). We found 75 specific appraisals, i.e. reflecting on actions or events that could be implemented in practice and could change it. These appraisals accounted for $41.43 \%$ of the total (15 articles). On the other hand, 106 fragments were coded as general, unrelated to action (global appraisals, accounting for $34.25 \%$, or 62 articles). Absence of appraisal (not having any indication of what worked well) was found in 44 accounts $(24.30 \% ; 29$ articles). With respect to obstacles, we identified nine $(18.36 \%)$ accounts that could be classified as highly recursive reflections.

\section{Conclusions}

In this study we attempted to explore the notion of teacher reflection by looking at what is said (theoretically), what is known (from research), and what is done (from teacher accounts of reflection). Our first comparison dealt with identifying shared key characteristics of teacher reflection found in theoretical literature to determine its grounding in research. A second comparison dealt with the empirically substantiated proposals to enhance or promote reflection in teacher practice. A third comparison linked teacher accounts of their refection with respect to the identified key characteristics.

Our findings indicate the following:

\section{What is known and what is stated}

We found that teacher reflection on action (TRA), despite its varied definitions, is either conceived as a deliberate problem-solving process in which a teacher engages in a (re)analysis of practice based on inquiry processes, or alternatively, it is conceived as a meta-cognitive process of thinking (planning, reviewing and (e)valuating) with respect to and directly associated with practice. We expected that the theoretical articles shared a certain understanding for grounding and empirically substantiating knowledge about the concept of reflection, and that teachers were presented with this validated knowledge for their practice. However, we found that what is 'known', i.e. empirically substantiated, for TRA has been studied only (1) in fragments and not as a whole process; and (2) mainly for non-key aspects.

In more detail we found that: 


\section{Reflective processes are studied in a fragmentary way}

In the studies we reviewed, TRA was not investigated as an interconnected process of deliberate thought, action, and problem solving (as its definition signifies). Most studies only dealt with specific aspects; that is, they fragment teacher reflection (probably for reasons of study), but this implies that they only tell 'part of the story' (Kane et al., 2002). Most studies tend to focus on teacher thoughts (beliefs and conceptions) rather than what teachers actually do (performed action); which could point to a blind spot in carrying out research (Tillema, Orland Barak \& Mena Marcos, 2008).

\section{Reflective features studied are diverse}

In studies on reflection many different issues are under inspection, i.e. collaboration processes, critical analysis, permanent education or the mastery of specific knowledge, but few specifically address key aspects with regard to procedures of reflection, its contents or its principles and use. Our selection was able to identify only a few empirical studies that focused on key features of reflection, and those that did hardly provided any data on them, i.e. on the practical inquiry processes. In addition, most studies provide knowledge through framed research designs: using specific data collection instruments (i.e. vignettes, critical incidents, etc.). This practice points to a possible dilemma between what is investigated in a natural and authentic way versus data collected in a contrived way.

\section{Is what is proposed based on what is known?}

In the reviewed studies, only very few proposals promoting reflection on action were specific enough to help teachers put the proposal in practice. A typical example to be followed by teachers is:

This means: starting off from practice to analyse situations, define problems, create procedures, question norms, rules and strategies frequently and automatically, and explain intervention and reflection procedures throughout action ... (Pérez Gómez, 1988 161(1), p. 11)

Most articles specify their definitions of reflection but not how to use the proposed principles; and when dealing with procedures, there is little or no detail or substance. That is, studies do not concretely describe how to enact proposals or indicate what teaching activities are to be considered. This suggests there is an issue in how teachers can use notions from theory and build them into action to sustain their TRA processes. What we saw instead was that the articles focused on defining attributes, stressing importance and noting limitations $(69.31 \%$ of the accounts). This can be problematic if we bear in mind that the actual object of teacher reflection is a process to generate knowledge.

Moreover, our analyses show that a large part of the messages transmitted to teachers (in journals aimed at teacher development) is not grounded empirically or backed up by theory. What, then, are proposals based on? Our analyses reveal that barely $10 \%$ is empirically founded; $54.4 \%$ is based on self-created knowledge by the authors themselves. The explicit empirically based proposals $(6.39 \%)$, however, only seldom offer detail on the feasibility of proposals. This leads us to conclude that teachers 
receive very little information to help them verify a proposal or determine the circumstances for applying it appropriately.

\section{What is actually done with what is stated?}

Teachers who present their reflection on action publicly (in journals) can be considered to be either directly or indirectly working with a model of reflection. We therefore tried to determine whether the key characteristics of reflection were present in their accounts, either deliberately or implicitly. However:

- There were several very different patterns of reflection.

- These patterns were not complete and recursive.

- Each one of the patterns was strongly linked to values and beliefs.

- A full action research or problem-solving cycle was hardly ever found.

What needs to be noted from the teacher accounts is the enormous variability in carrying out reflection on action. The fact that there are 13 different reflection patterns shows that there are no definite or fixed modes for using reflection on action. Furthermore, it can be noted that few patterns are complete, i.e. only $18.36 \%$ uses the four key features of reflection on action. The value-laden character of reflection seems very typical in that reflection has as its main purpose for teachers to legitimize specific goals $(33.84 \%)$. That is to say, the content in teachers' reflective accounts refers to beliefs and values guiding their reflective activity.

This leads us to conclude that teachers pay attention to the outcomes of reflection more than to the process itself. Indeed, most reflective accounts are more narrative than analytical or systematic. They depict reflection on action as a process of specifying goals and intentions of action that can justify what has been done.

This study was intended to illuminate the concept of teacher reflection as used in different domains by looking for correspondences among them. It was expected that alignment among (1) grounded or empirically validated theory; (2) professional development; and (3) teacher practice was present in order to provide a firm foundation for the use of reflection on action. At least two outcomes with regard to actual reflection on action can be noted: first, on the one hand, teacher reflection acts to justify practice. Reflective activity is strongly associated with values. Second, teacher reflection on action is intended to prescribe future action rather than inquire into or provide a record of what has happened.

Thus, little is known about the full, i.e. 'complete' and 'recursive' process of teacher reflection, since most studies deal with fragmented aspects or non-key features of reflection that do not allow for complete evaluation of teacher reflection on action as an inquiry oriented or action research cycle. It suggests that what has been done (in research) does not adequately describe what has been claimed (in theory) or what has been acted upon (in teaching); at least the three domains do not match appropriately. It seems that the research on reflection (i.e. in models of reflection) differs from (patterns of) what teachers do when they attempt to revise a plan, review their actions or assess whether they have achieved what they intended. Reflection is intended to justify teaching that corresponds to an ideal (a teacher value) rather than to a specific problem. Considering the cyclical nature of the process, we found that actual reflective activity operates in a linear way: it does not review the problem or look back. This is an important finding since it may mean that reflection on action cannot be readily 
equated with inquiry-oriented or problem-solving action research (Cochran-Smith \& Lytle, 1993).

This finding suggests there is a need to re-evaluate the concept of teacher reflection on action, because what has been claimed as key characteristics and guiding notions behind the concept, i.e. deliberate scrutiny of practice, are either not performed (in an analytical, specific, and self-critical way) or not studied as an unfragmented cyclical process. This may require revision of the existing research based models on reflection or implementation of changes in reflective teaching practices.

\section{Notes on contributors}

Juan José Mena Marcos is Adjunct professor in the Department of Education at the University of Salamanca. His areas of study are focused on Teacher Education, educational practice and teacher reflection.

Emilio Sánchez Miguel is Professor of Educational Psychology at the University of Salamanca (Department of Developmental and Educational Psychology). He is an expert in reading comprehension and also in the analysis of educational practice.

Harm H. Tillema is a senior lecturer at Leiden University, The Netherlands. His main field of expertise is teacher development and assessment.

\section{References}

Bereiter, C. (2002). Education and mind in the knowledge age. Mahwah, NJ: Lawrence Erlbaum Associates.

Braun, J.A., \& Crumpler, T.P. (2004). The social memoir: An analysis of developing reflective ability in a pre-service methods course. Teaching and Teacher Education, 20, 59-75.

Butler, D., Novak, H., Jarvis-Selinger, S., \& Beckingham, B. (2004). Collaboration and selfregulation in teachers' professional development. Teaching and Teacher Education, 20, 435-455.

Carr, W. (1989). Action research: Ten years on. Journal of Curriculum Studies, 21(1), 85-90.

Carr, W., \& Kemmis, S. (1988). Becoming critical: Knowing through action research. Waurn Ponds, Victoria: Deakin University Press.

Clarke, D., \& Hollingsworth, H. (2002). Elaborating a model of teacher professional growth. Teaching and Teacher Education, 18, 947-967.

Clarke, A. (2006). The nature and substance of cooperating teacher reflection. Teaching and Teacher Education, 22, 910-921.

Cochran-Smith, M., \& Lytle, S. (1993). Research on teaching and teacher research: The issues that divide. Educational Researcher, 19(2), 2-11.

Cochran-Smith, M., \& Zeichner, K.M. (2005) Studying teacher education; report of the AERA Panel on Research and Teacher Education. Mahwah, NJ: Lawrence Erlbaum.

Edwards, A., Gilroy, P., \& Hartley, D. (2002). Rethinking teacher education, collaborative responses to uncertainty. London: Routledge Falmer.

Elliott, J. (1991). Action research for educational change. Buckingham: Open University Press.

Griffin, M.L. (2003). Using critical incidents to promote and assess reflective thinking in preservice teachers. Reflective Practice, 4(2), 207-220.

Johnson, B. (1995). Why conduct action research? Teaching and Change, 3(2), 90-104.

Kane, R., Sandretto, S., \& Heath, C. (2002). Telling half the story: A critical review of research on the teaching beliefs and practices of university academics. Review of Educational Research, 72(2), 177-228.

Kember, D., Jones, A., Loke, A., Mckay, J., Sinclair, K., Tse, H., Webb, C., Wong, F., Wong, M., \& Kember, D., \& Lung, D.Y.P. (2000). Development of a questionnaire to measure the level of reflective thinking. Assessment \& Evaluation in Higher Education, 25(4), 382-395 
Kemmis, S., \& McTaggart, R. (eds.). (1988). The action research planner, (3rd ed.) Victoria: Deakin University.

Kessels, J.P.A.M., \& Korthagen, F.A.J. (1996). The relationship between theory and practice: Back to the classics. Educational Researcher, 25(3), 17-22.

King, P.M., \& Kitchener, K.S. (2004). Reflective judgement: Theory and research on the development of epistemic assumptions through adulthood. Educational Psychologist, 39(1), 5-18.

LaBoskey, V. (1994). Development of reflective practice. New York: Teachers College, Columbia University.

Leinhardt, G. (1988). Situated knowledge and expertise in teaching. In J. Calderhead (ed.). Teachers' professional learning (pp. 146-168). London: Falmer Press.

Lewin, K. (1946) Action research and minority problems. Journal of Social Issues, 2, 34-46.

Liston, D.P., \& Zeichner, K.M. (1993). Formación del profesorado y condiciones sociales de la escolarización. Madrid: Morata.

Little, S.L., \& Cochran-Smith, M. (1990). Learning from teacher research: A working typology. Teachers College Record, 92(1), 83-103.

Masui, C., \& De Corte, E. (2005). Learning to reflect and to attribute constructively as basic components of self-regulated learning. British Journal of Educational Psychology, 75, 351-372.

McAlpine, L., \& Weston, C. (2000). Reflection: Issues related to improving professors' teaching and students' learning. Instructional Science, 28, 363-385.

McLellan, E. (2004). How reflective is the academic essay? Studies in Higher Education, 29(1), 76-89.

McNiff, J. (1998). Action research: Principles and practice. London: Routledge. Falmer.

Mena Marcos, J., \& Tillema, H.H. (2006). Studying studies on teacher reflection and action: An appraisal of research contributions. Educational Research Review, 1(2), 112-132.

Mudler, I., Swaak, J., \& Kessels, J. (2004). In search of reflective behavior and shared understanding in ad hoc expert teams. Cyber Psychology \& Behavior, 7(2), 141-154.

Osterman, K. (1990). Reflective practice: A new agenda for education. Education and urban society, 22(2), 133-152.

Pérez Gómez, A.I. (1988). Autonomía y formación para la diversidad. Cuadernos de Pedagogía, 161(1), 8-11.

Price, J.N., \& Valli, L. (2005). Preservice teachers becoming agents of change. Pedagogical implications for action research. Journal of Teacher Education, 56(1), 57-72.

Sánchez, E. (2001). Ayudando a ayudar: El reto de la investigación educativa. Cultura y Educación, 13, 249-266.

Schön, D.A. (1983). The reflective practitioner: How professionals think in action. New York: Basic Books.

Schön, D.A. (1984/1992). La formación de profesionales reflexivos. Hacia un nuevo diseño de la enseñanza y el aprendizaje en las profesiones. Barcelona: Paidós.

Schön, D.A. (1987). Educating the reflective practitioner toward a new design for teaching and learning in the professions. San Francisco, CA: Jossey-Bass.

Schön, D.A. (1987/1992). El profesional reflexivo. Barcelona: Paidós.

Shulman, L.S. (1987). Knowledge and teaching: Foundations of the new reform. Harvard Educational Review, 19(2), 4-14.

Smith, K., \& Tillema, H. (2001). Long-term influence of portfolios on professional development. Scandinavian Journal of Educational Research, 45(2), 183-203.

Tillema H.H. (2006). Constructing knowledge in professional conversations. The role of beliefs on knowledge and knowing. Learning and Instruction, 16(6), 592-608.

Tillema, H.H., Orland Barak L., \& Mena Marcos, J. (2008). Researchers working in the interpretive zone. Ethnography and Education, 3(1), 49-62.

Van Manen, M. (1995). Epistemology of reflective practice. Teachers and Teaching: Theory and Practice, $1(1), 33-50$.

Westberg, J. (2001). Helping learners become reflective practitioners. Education for Health, $14(2), 313-321$.

Zeichner, K. M.(1993). Action research: Personal renewal and social reconstruction. Educational Action Research, 1, 199-219.

Ziegahn, L. (2005) Critical reflection on cultural difference in the computer conference. Adult Education Quarterly, 56, 39-64. 